\title{
ON RELATIVE GEOMETRIC INEQUALITIES
}

\author{
A. Cerdán, U. Schnell and S. Segura Gomis
}

Abstract. Let $E$ be a subset of a convex, open, bounded, planar set $G$. Let $P(E, G)$ be the relative perimeter of $E$ (the length of the boundary of $E$ contained in $G$ ). We obtain relative geometric inequalities comparing the relative perimeter of $E$ with the relative diameter of $E$ and with its relative inradius. We prove the existence of both extremal sets and maximizers for these inequalities and describe the geometric properties of them. We also give a characterization of planar convex sets of constant width in terms of the geometric constant corresponding to the relative diameter.

Mathematics subject classification (2000): 52A40, 52A10.

Key words and phrases: Relative geometric inequalities, diameter, inradius, constant width, extremal sets.

\section{REFERENCES}

[1] A. CiAnchI, On relative isoperimetric inequalities in the plane, Boll. Unione Mat. Italiana, 7 3-B (1989), 289-325.

[2] H. T. CROFT, K. J. FAlCONER AND R. K. GuY, Unsolved problems in Geometry, Springer, Berlin, 1991.

[3] G. D. CHAKERIAN AND H. GROEMER, Convex bodies of constant width, in: Convexity and its applications, 49-96, eds P. M. Gruber and J. M. Wills, Birkhäuser, Basel, 1983.

[4] C. PERI, On relative isoperimetric inequalities, Conferenze del Seminario di Matematica dell'Università di Bari, 279.

[5] A. Rosenthal and O. Szasz, Eine Extremal Eigenschaft der Kurven Konstanter Breite, Jber. Deutsch. Math.-Vereinig. 25 (1917), 278-282. 